\title{
Aspects of the biology of Ephestia cautella and Tribolium castaneum on fermented stored cocoa beans
}

\author{
E. A. OYEWO* \& B. O. AMO \\ (E.A.O \& B.O.A.: Department of Crop and Soil Sciences, Kwame Nkrumah University of \\ Science and Technology, Kumasi) \\ *Corresponding author's email: emmaoyewo@hotmail.com
}

\begin{abstract}
Ephestia cautella (Walker) (Lepidotera: Pyralidae) and Tribolium castaneum (Herbst) (Coleoptera: Tenebrionidae) are pests associated with dried fermented stored cocoa beans that cause extensive damage. The biology of these pests on cocoa beans in Ghana has not been well documented, especially on $T$. castaneum. Due to climate changes and improved/hybrid seedlings being released to farmers, it has become necessary to re-evaluate the biology and damage of these pests on fermented stored cocoa beans. The experiments were conducted in the Insectary laboratory of the Department of Crop and Soil Sciences, Kwame Nkrumah University of Science and Technology, Kumasi, Ghana. Paired 0-1 day old E. cautella adults were placed in Petri dishes and covered with Kilner jars. The eggs laid daily by each female were carefully transferred onto $15 \mathrm{~g}$ cocoa beans in Petri dishes. The egg incubation period was four days, 31 days larval period and the pupal period of seven days. Unmated adult males lived for 12.1 days and females 7.9; mated males lived for 10.9 days and females 5.5. Paired T. castaneum were introduced on $2.0 \mathrm{~g}$ broken cocoa beans in Petri dishes. The average incubation period was nine days, 40 days larval period, and pupal period of five days.
\end{abstract}

Keywords: Ephestia cautella; Tribolium castaneum; developmental period; life cycle; cocoa beans

Original scientific paper. Received 02 Aug 2019; revised 20 Feb 2020

\section{Introduction}

Ephestia cautella (Walker) (Lepidotera: Pyralidae) is commonly referred to as the almond moth or tropical warehouse moth. It is a small, stored-product pest that infests flour, bran, oats, and other grains, as well as dried fruits or nuts. Tribolium castaneum (Herbst) (Coleoptera: Tenebrionidae), commonly referred to as the Rust-red flour beetle, is one of the most common insect pests of storedproducts (Arbogast, 1991; Ahmad et al., 2012). Tribolium castaneum is a polyphagous cosmopolitan pest. It thrives best in cereal products and other dried foods, processed or stored, and it even dwells in the flour mills. It is often the most common species in the pest complex attacking stored wheat. It has been reported to feed on a wide variety of products including flour, meals, cereals, chocolate, cocoa, animal matter, wood, dried fruit, vegetables, drugs, damaged seeds, cracked nuts, as well as whole-wheat flour (Good, 1936; Mason, 2003).

T. castaneum cannot feed on entire, undamaged grain because their mandibles are not strong enough to chew through the tough

Ghana Jnl Agric. Sci. 55 (1), 14 - 21

GJAS is an Open Access Journal and distributed under the terms of the Creative Commons (CC) License [CC BY 4.0] 
outer coating. Practically all lots of grain, however, contain a certain percentage of broken kernels, so these beetles may be found infesting almost every known kind of grain (Good, 1936). It is considered a secondary pest, requiring prior infestation by internal feeders or infest grains damaged during the harvesting operation (Karunakaran et al., 2004). However, E. cautella is a primary pest and cause damage to stored whole grains or nuts. It is a very destructive pest of initial infestation that goes unnoticed.

Jonfia-Essien (2001) listed E. cautella and $T$. castaneum among the 11 pests associated with cocoa. Cocoa (Theobroma cacao L.) is the backbone of Ghana's economy, a commodity that represent the most significant export crop (Tracy, 2009). It accounts for $8 \%$ of the country's GDP and $30 \%$ of the total export earnings (GAIN, 2012). These two pests, more especially $E$. cautella can cause serious economic and nutritional loss in storage if not periodically treated with chemicals, mostly by fumigating with aluminum phosphide, which is practiced in Ghana. Although safe, it has been associated with residue and maximum residue levels (MRLs) determination has now become a requirement in the international cocoa trade.

The life cycle of $T$. castaneum varies depending on the products it feeds upon or according to the food the larvae feed on because it is the active feeding stage of the insect as well as temperature (Good, 1936). The egg and pupal development are not affected by diet and relative humidity. The larval developmental period is, however, influenced by diet, temperature and relative humidity. This is because the larval stage is the active and feeding stage of the immature insect. Rebecca and Thomas (2003) reported a life cycle of 4090 days while Dhaliwal et al. (2006) reported that the developmental period of the egg to the adult was 26-30 days in summer, but it was longer under unfavourable condition of temperature and food. This beetle could breed throughout the year until the nutritional quality of the food media is diminished.

Female beetles lay 300 - 400 eggs directly into flour or other food during a period of five to eight months (2-3 eggs per day). However, it may lay about 1000 eggs over most of their lifetime of two to over three years (Good, 1936; Shazali \& Smith, 1986; Rees, 2004). It tends to lay more eggs in larger amounts of flour (Campbell \& Runnion, 2003; Mason, 2003; Rees, 2004; Anon, 2009). Fully grown larvae transform into naked pupae without any form of protection. At the optimum temperature of $35^{\circ} \mathrm{C}$, the development time are 3.1 days for eggs, 16 days for larvae and 4.5 days for pupae at RH $60-80 \%$ (Shazali \& Smith, 1986).

The complete life cycle of $E$. cautella under laboratory conditions takes about 50 days on stored cocoa beans. It lays an average of 100 eggs over its average four days life span. The incubation period of the egg is four days, the larval period is 38 days and the pupal stage is eight days (Rawnsley, 1959; Mould \& Rawnsley, 1960; Amuh,1961). In addition to cocoa beans, E. cautella has been recorded on maize, groundnuts, palm kernels copra and cowpeas. All these food crops appear to be more suitable than cocoa for the development of the insect, because the life cycle on them took a much shorter period. For example, on maize, the life cycle was completed in about 30 days (Amuh, 1961). However, cocoa beans seem to be the preferred commodity, probably because of the odour. E. cautella can cause almost $29 \%$ damage to fermented stored cocoa beans over a period of four months. Increased $E$. cautella and $T$. castaneum infestation also increase 
the levels of free fatty acid (FFA) above the international recommended threshold of $1.75 \%$ thereby making the product unwholesome for cocoa butter processing (Oyewo \& Amo, 2018).

The biology and life cycle of T. castaneum on stored cocoa has not been thoroughly investigated and there has not been any current study or update on the biology and life cycle of E. cautella on the now introduced new varieties and hybrid cocoa beans in Ghana. Most insect do well or develop rapidly when food varieties are improved. Knowing the biology and life cycle of these two insects on stored cocoa beans will offer better-informed decision on insect build upon and which control measures can be taken, whether to fumigate or otherwise. With adequate information on the biology and life cycle of $T$. castaneum and E. cautella over a period of time on standard fermented cocoa beans in storage lacking, the study was therefore conducted.

\section{Material and Methods}

The experiments were conducted at the Entomology Laboratory of the Department of Crop and Soil Sciences of the Kwame Nkrumah University of Science and Technology (KNUST). The temperature and relative humidity range were $27^{\circ} \mathrm{C}$ to $36.5^{\circ} \mathrm{C}$ and $40 \%$ to $85 \%$, respectively.

\section{Source of experimental materials}

Adult E. cautella and T. castaneum for the experiment were cultured in two different 1.5 L Kilner jars from a laboratory diet of finely ground maize, wheat bran and glycerol in the ratio of $8: 8: 1(\mathrm{w} / \mathrm{w})$ in the Insectary of the Department of Crop and Soil Sciences, KNUST. In another two different 1.5 L Kilner $1 / 2$ filled with cocoa beans, adult E. cautella were cultured. The cocoa beans were provided by the Warehouse of Quality Control Division (QCD) of COCOCBOD-Kaase (Kumasi) for the study. The beans were placed in an EVERmed (ULF $440 \mathrm{~W}$ PRO 2) freezer at $-80^{\circ} \mathrm{C}$ for six days to kill any stages of insects that might be present. The beans were spread out in the laboratory to equilibrate to ambient temperature. The measured moisture content of the cocoa beans was $10 \%$. All damaged or defective beans were removed, and only undamaged beans were used for the experiments.

Experiment 1: Biology of Ephestia cautella on cocoa beans

Developmental period of the E. cautella on cocoa beans

A pair (male: female) of newly emerged (< 1-day old) adults of E. cautella from the laboratory diet culture was released into a 1 L Kilner jar. The Kilner jar was inverted and placed over a $0.9 \mathrm{~cm}$ diameter Petri dish lined with black papers to provide the colour contrast of the white/creamy eggs. The eggs laid daily by each female were carefully transferred onto $15 \mathrm{~g}$ cocoa beans in Petri dishes with the aid of a horse brush. The set-up was replicated 10 times.

The number of days the first instar larvae emerged (incubation period) were recorded each morning. The lid of each Petri dish was removed and replaced with an inverted 1 L Kilner jar. After all the first instar had penetrated the cocoa beans, the beans were transferred into $0.5 \mathrm{~L}$ Kilner jars and closely monitored for the developmental period of larvae and pupae of each replicate. In a similar set-up, as control, the cocoa beans were replaced with laboratory diet. 


\section{Experiment 2}

Fecundity and longevity of E. cautella adults on cocoa beans

Newly emerged adults from cocoa beans culture were paired into inverted $1 \mathrm{~L}$ Kilner jar on Petri dishes lined with black papers. The number of eggs laid by each female was recorded daily by replacing the Petri dishes until no more eggs were laid. Adults' longevity for mated individuals was recorded. In another set-up, unmated adults were separated, and their longevity recorded. As a control experiment, similar set-ups of adults reared on laboratory diet were used. All experiments were replicated 10 times.

Experiment 3: Biology of Tribolium castaneum on cocoa beans

Developmental period of the insect on cocoa beans

Newly emerged adults of $T$. castaneum were paired (male: female) and introduced on $2.0 \mathrm{~g}$ broken cocoa beans in $9 \mathrm{~cm}$ diameter Petri dish lined with black papers. Broken beans were used because $T$. castaneum is secondary pest, requiring prior infestation by an internal feeder.

The set-up was monitored daily for the presence of first instar larvae. The incubation period was recorded, the females laid eggs the next day after the pair were introduced. The adults introduced were removed after two weeks. The developmental period of the larvae and pupae were recorded. The set-up was replicated 10 times. The total developmental period of the insect was determined on each replicate.

\section{Results}

Fecundity of E. cautella on cocoa beans

The highest number of eggs laid by E. cautella reared on cocoa beans was 157 (and that on laboratory diet was 188) and it was during the first day. The number of eggs laid decreased as the day progressed. As many as 310 eggs could be laid within the four-day lying period on cocoa beans and 358 eggs if adults are cultured on laboratory diet. There were significant differences $(\mathrm{P}<0.05)$ between eggs laid on the first, second and third days but there were no significant differences between the third and fourth days of eggs laid (Table 1).

Longevity of adult E. cautella reared on stored cocoa beans

The results on the longevity of adult $E$. cautella reared on cocoa beans are shown in Table 2. The mean longevity (days) of mated females and mated males were 5.5 and 10.9 , respectively. The mean longevity of unmated females and unmated males were also 7.9 and 12.1, respectively. There were significant differences $(\mathrm{P}<0.05)$ in the mean longevity between unmated males and unmated females but there were no significant differences $(\mathrm{P}>0.05)$ in the mean longevity among unmated males and mated males, as well as unmated females. 


\section{TABLE 1}

Fecundity of Ephestia cautella reared

\begin{tabular}{lrr}
\hline \multicolumn{2}{c}{ Days } & \multicolumn{2}{c}{ Mean number of eggs laid \pm SE } \\
& On cocoa beans & On laboratory diet \\
\hline 1 & $93.6 \pm 12.28$ & $122.90 \pm 12.21$ \\
& $(43-157)^{*}$ & $(64-188)^{*}$ \\
2 & $52.6 \pm 7.42$ & $66.40 \pm 6.51$ \\
& $(21-85)^{*}$ & $(30-98)^{*}$ \\
3 & $27.5 \pm 4.31$ & $28.20 \pm 4.58$ \\
& $(9-61)^{*}$ & $(9-59)^{*}$ \\
4 & $10.1 \pm 2.31$ & $(3-33)^{*}$ \\
& $(1-21)^{*}$ & \\
& & \\
$\mathrm{~N}=10$ & & 21.33 \\
LSD $(0.05)$ & 21.73 & \\
\hline
\end{tabular}

* Range of eggs laid

$\mathrm{N}=$ number of replicates
TABLE 2

Longevity of adult Ephestia cautella reared

Treatment Longevity (days) Mean \pm SE

On cocoa beans On laboratory diet

\begin{tabular}{lll}
\hline Unmated males & $12.1 \pm 1.13$ & $12.30 \pm 0.75$
\end{tabular}

$(7-17) *$

$(9-17) *$

Mated males $\quad 10.9 \pm 1.86$

$11.90 \pm 1.13$

$(5-22)^{*}$

$(5-18)^{*}$

Unmated females

$7.9 \pm 0.94$

$(5-13)^{*}$

$8.40 \pm 0.57$

$5.5 \pm 0.37$

$(4-8)^{*}$

$(6-12)^{*}$

Mated females

$5.30 \pm 0.21$

$\mathrm{N}=10$

$\operatorname{LSD}(0.05)$

3.46

$(4-6)^{*}$
*Range of longevity of adults

$\mathrm{N}=$ number of replicates

TABLE 3

Developmental period of Ephestia cautella on stored cocoa beans and laboratory diet

Mean \pm SE (Days)

\begin{tabular}{lllll}
\hline Treatment & Incubation period & Larval period & Pupal period & Total development \\
Cocoa beans & $3.80 \pm 0.13$ & $30.90 \pm 1.33$ & $7.20 \pm 0.39$ & $42.00 \pm 1.22$ \\
& $(3-4)^{*}$ & $(24-38)^{*}$ & $(6-9)^{*}$ & $(36-47)^{*}$ \\
Laboratory diet & $\begin{array}{l}3.73 \pm 0.15 \\
(3-4) *\end{array}$ & $\begin{array}{l}19.50 \pm 0.17 \\
(19-20)^{*}\end{array}$ & $\begin{array}{l}7.00 \pm 0.20 \\
(6-8)^{*}\end{array}$ & $\begin{array}{l}(28-32)^{*} \\
\text { N=10 }\end{array}$ \\
LSD $(0.05)$ & 0.43 & 2.83 & 0.95 & 2.84 \\
\hline
\end{tabular}

TABLE 4

Developmental period of Tribolium castaneum reared on cocoa beans

\begin{tabular}{llll}
\hline Incubation Period & Laval Period & $\begin{array}{l}\text { Mean Day } \pm \text { SE } \\
\text { Pupal Period }\end{array}$ & Total Development \\
\hline $8.7 \pm 0.47$ & $40.3 \pm 0.99$ & $5.1 \pm 0.31$ & $54.1 \pm 1.48$ \\
$(7-12) *$ & $(36-45)^{*}$ & $(4-7) *$ & $(47-63) *$ \\
$\mathrm{~N}=10$ & & & \\
\hline
\end{tabular}

*The range of development

$\mathrm{N}=$ number of replicates 


\section{Discussion}

The number of eggs laid by E. cautella reared on cocoa beans was significantly lower than the number reared on laboratory diet. Almost one half of the total number of eggs were laid on the first day and $3 / 4$ after the second day. This study confirmed the reports by Rawnsley (1959), Mould, Rawnsley (1960) and Amuh (1961) that E. cautella laid more eggs on cocoa beans in the first two days during a 4-day egg laying period. Nevertheless, the average total number of eggs (183.80) laid by female E. cautella reared on cocoa beans in this study was comparatively higher than the 100 eggs reported by Rawnsley (1959) and Amuh (1970). However, E. cautella reared on laboratory diet laid an average of 235 eggs on cocoa beans.

The unmated male adults of E. cautella had the longest live span whilst the mated females were extremely short. The results were similar to the findings of Oyedokun et al. (2012). However, in this study, the unmated lived for 12.1 days, which was far longer than the 9.75 recorded by Oyedokun et al. (2012). Ragland and Sohal (1973) observed that aging in the housefly is greatly influenced by physical activity but, restriction of physical activity and elimination of mating by confining flies individually doubles the mean and maximum lifespans of males. The same phenomenon could be attributed to increased longevity in unmated males and females of $E$. cautella.

It was observed that E. cautella developed faster on the laboratory diet (30 days) over cocoa beans (42). This means the laboratory diet was a preferred and more palatable choice. Some of the damaged cocoa beans had various stages of larvae developing within them when a cut test was done. E. cautella eggs hatch outside the beans and the first instar larvae crawl around the cocoa and eventually enters the beans by biting through the nib. The results of the larval developmental period of E. cautella reared on cocoa beans did not corroborate the findings of Rawnsley (1959), Mould and Rawnsley (1960) and Amuh (1961). While egg incubation period (four days) and pupal stages (seven days) were similar, the larval developmental period of 38 days greatly varied from 31 days recorded in this study and the total developmental period was 42 as compared to 50 days under laboratory conditions.

For T. castaneum, it was observed that after nine days (7 to 12), the first instar larvae emerged on the beans after oviposition. The larvae develop outside the food media, nibbling in and/or outside the broken cocoa beans, pulverizing it. The larval developmental period was 40 days (36 to 45 ), while that of the pupa was 4-7 days with a mean of 5.1. The total developmental period from egg to adult emergence was 54.1 days on cocoa. The pupal period in this study was similar to the findings of Hassan and Khan (1988) who reported a pupal period of 5.23 days on wheat flour (at $30^{\circ} \mathrm{C}$ and $85 \%$ R.H). This confirms the report of Good (1936) and Howe (1956) that larval food had no effect on the pupal of T. castaneum.

\section{Conclusion}

In this study, a single E. cautella female could lay as much as 310 eggs (average 184) in its average life span of 5.5 days. The study revealed that the number of eggs laid depended on food fed by larvae prior to adults infesting cocoa beans. It could be an alternate host before moving on to attack cocoa beans being dried on mats, transported or stored in warehouses. Coupled with a much shorter larval and total developmental including high hatchability potential, a few adults could massively cause 
destruction to cocoa beans both qualitatively and quantitatively. The shorter developmental period suggests that the new improved/hybrid varieties are more suitable and preferred by $E$. cautella.

The biology and life cycle of $T$. castaneum on improved/hybrid cocoa variety was investigated

E. cautella has a shorter average developmental period of 42 days on cocoa as compared to 54 days of $T$. castaneum. It also lays more eggs and has higher hatchability as compared to T. castaneum within a shorter period of time. Thus, E. cautella has the potential to cause more destruction to the now developed hybrid cocoa beans.

\section{REFERENCES}

Ahmad, F., Walter, G. H. \& Raghu, S. (2012) Comparative performance of Tribolium castaneum (Herbst) (Coleoptera: Tenebrionidae) across populations, resource types and structural forms of those resources. Journal of Stored Products Research 48, $73-80$.

Arbogast, R. T. (1991) Beetles: Coleoptera. Gorham JR, editor. FDA Technical Bulletin \#4.

Amuh, I. K. A. (1961) Build up of insect infestation in cocoa beans during storage, Unpublished report to the Ghana Marketing Board.

Amuh, I. K. A. (1970) Potentialities for Application of the Sterile-Male Technique to the Control of the Cocoa Moth, Cadra cautella Walk. Proc. Panel Application of Induced Sterility for the control of Lepidopterous Population. Vienna, $7-11$.

Anonymous. (2009) Red flour beetle Tribolium castaneum (Herbst.) Canadian Grain Commission.http://www.grainscanada.gc.ca/ storage-entrepose/pipirp/rfbtrfeng.htm. Accessed on 17 $7^{\text {th }}$ October, 2015.
Campbell, J. F. \& Runnion, C. (2003) Patch exploitation by female red flour beetle, Tribolium castaneum. Journal of Insect Science 3, 20 - 24.

Dhaliwal, G. S., Ram, S. \& Chhillar, B. S. (2006) Store grain pest. pp. 356-354. Issue in Essentials of Agricultural Entomology.

GAIN. (2012) Cocoa Annual Report, Product Brief Report Prepared by Ashitey Elmasoeur of USDA Foreign Agricultural Service. GAIN Report Number GH 1202, Accra.

Good, N. E. (1936) The flour beetles of the genus Tribolium. United States Department of Agriculture Washington, D. C; Technical Bulletin no. 489.

Hassan, M. \& Khan, A. R. (1988) Growth and development of the red flour beetle, Tribolium castaneum Herbst., on red lentil flour, Lens esculenta. Bangladesh - Journal of Zoology 16 (2), $177-180$.

Howe, R. W. (1956) The effect of temperature and humidity on the rate of development and mortality of Tribolium castaneum (Herbst) (Coleoptera, Tenebrionidae), Annals of Applied Biology 44 (2), 356 - 368.

Jonfia-Essien, W. A. (2001) The effect of storage on the quality of cocoa beans. Internal Report, Ghana Cocoa Board, Accra, Ghana. Accessed on $20^{\text {th }}$ March, 2015

Karunakaran, C., Jayas, D. S. \& White, N. D. G. (2004) Identification of wheat kernels damaged by the red flour beetle using x-ray images. Biosystems Engineering 87 (3), 267 -274 .

Mason, L. J. (2003) Grain Insect Fact Sheet E-224-W: Red and Confused Flour Beetles, Tribolium castaneum (Bhst.) and Tribolium cunfusum Duval. Purdue University, Department of Entomology. Accessed on 24 ${ }^{\text {th }}$ July, 2015. 
Mould, H. A. \& Rawnsley, J. (1960) Experiments on kill of Ephestia cautella adults using Thermal fogs of Risella 17 oil containing different concentrations' of (a) pyrethrins and (b) Synergised pyrethrins. Ghana Cocoa Marketing Board. Insect Control Unit. Publication 13.

Oyewo, E. A. \& Amo, B. O. (2018) Assessment of the damage caused by Ephestia cautella (Walker) to stored cocoa beans. Ghana Journal of Agricultural Science 52, 25 - 31.

Ragland, S. S. \& Sohal, R. S. (1973) Mating behavior, physical activity and aging in the housefly, Musca domestica. Experimental Gerontology 8 (3), 135 - 45.

Rawnsley, J. (1959) Preliminary studies on the mating and egg-laying habits of the cocoa moth,Ephestia cautella, Ghana cocoa marketing board Insect Control Unit, Publication 5, 1 -3 .
Rebecca, B. \& Thomas, R. F. (2000) Feature Creatures Entomology and Nematology. http://entnemdept.ufl.edu/creatures/urban/ beetles/red flour beetle.htm

Rees, D. (2004) Insects of Stored Products. CSIRO Publishing, Collingwood, Australia. pp. 181.

Shazali, M. E. H. \& Smith, R. H. (1986) Life history studies of externally feeding pests of stored sorghum: Corcyra cephalonica (Staint.) and Tribolium castaneum (HBST). Journal of Stored Products Research, 22 (2), 55 - 61.

Tracy, W. (2009) An African success story: Ghana's cocoa marketing system. IDS working paper 2009, (318). [Available on line] http://www. ids.ac.uk/gdr/cfs/pdfs/Wp318.pdf. Accessed on 12th October, 2015. 